\title{
Online Conferencing for Focus Group Discussions with Teenage Girls
}

\begin{abstract}
Purpose: The purpose of this paper is to examine the use of online conferencing platforms for focus group discussions with teenage girls.

Design/methodology/approach: The paper discusses the use of online conferencing for focus group discussions with Australian teenage girls aged 12 to 14 years who were participating in a study about their online interaction with friends. It examines both the practical application of online conferencing as a qualitative method as well as the inherent challenges of this context for youth research. Design decisions are explained and methods for ensuring rich contribution are detailed.
\end{abstract}

Findings: Online conferencing offers three distinct advantages for focus group work. First, the environment consciously engages participants in spontaneous interaction with other participants by using communication tools familiar to them. Second, elaborated discussion can be stimulated by introducing ideas and trends through visual mediums and artefacts. Three, the virtual setting provides remote access by the researcher which shifts power relationships, so discussions flow more naturally between participants.

Practical Implications: Outcomes indicate that online conferencing is an effective method for encouraging participants to share ideas and experiences about aspects of their lives that are often private and/or sensitive.

Originality/Value: Technological advances in online collaboration tools have resulted in an increased use of online conferencing platforms across disciplines especially for teaching and learning contexts. However, application of online conferencing for focus 
group discussions with young people has not received much attention. Research

presented here demonstrates that it is a useful tool for engaging teenage girls in focus group discussions.

\section{Introduction}

The clock ticked, no one asked a question. A few girls grew edgy and unsettled; there was a lot of hair twirling and body squirming from others. Eventually one girl raised her hand and asked, 'Why do you adults want to know what we do online?' A different girl piped up, 'Yah!?' There were agreement sounds and mumbling from others. When the group trickled past to collect project information sheets, two girls deliberately blocked the path to the materials. Meaningful looks were exchanged. Some of the girls who had already collected items left them on an empty chair near the door (Field Notes, Author, 2011).

Across disciplines, researchers have noted the difficulties of engaging young people in programs of qualitative study that require commitment to sharing personal experiences about topics significantly sensitive or taboo (see, for example, Nguyen et al., 2012). Participant recruitment can be an initial difficulty (see excerpt above) followed by other challenges including but not limited to ethical demands for under 18s (Author, 2016a), social and emotional wellbeing safeguards (Koocher, 2002), encouraging active participation and in-depth conversation (Barter and Renold, 2000; Danby et al., 2011), and sustaining participant commitment to the research (Bassett et al., 2008; Mallan et al., 2013). These issues were particularly salient in the research described in this paper.

\section{The Study}

The research described here is my doctoral work. The purpose of this study was to investigate Australian teenage girls' online participation with friends (Author, 2016a, 
2016b). The project aimed to better understand girls' online troubles such as cyberbullying and sexting by focusing on the dynamics of friendship. At the time (2011), cyberbullying and sexting were emerging as widespread practices with serious consequences for girls' safety and wellbeing (Cross et al., 2012). Even though research was beginning to highlight gender as a condition specific to these problems, most studies focused more broadly on prevalence figures, risk factors, measurement concerns, and definitional issues (Hinduja and Patchin, 2012). For this reason, most investigations were quantitative in nature. However, demands for more detailed explorations of young people's experience with online problems were growing. In particular, more in-depth investigation into the personal experiences of both girls and boys in online contexts were needed especially in light of early findings suggesting that gendered online social practices (Australian Communications and Media Authority [ACMA], 2008 and Livingstone and Haddon, 2009) influenced cyberbullying and sexting prevalence (Cross et al., 2009; Ringrose et al., 2013) Moreover, some of this same scholarship (Cross et al., 2009; Ringrose et al., 2013) was showing girls, especially girls aged 12 to 14 , as a demographic particularly susceptible to these concerns amongst peers and close friends. Therefore, the aim of the doctoral work was to investigate girls' online troubles by employing an approach that ensured focused and descriptive accounts of their time online with friends. The main objective was to generate representative examples of how girls aged 12 to 14 speak to each other, manage their online presence, and circumvent online troubles when communicating with friends.

Data was generated two stages. In the first stage, 130 Year 8 girls from four high schools in Queensland, Australia completed an online survey. The survey asked the girls 
questions about their online practices and strategies with friends. In stage two, 16 girls from one school participated in one of four focus group discussions held in an online conferencing facility. The methods and activities used to generate focus group discussions with teenage girls in the online conferencing context is the focus of this paper.

\section{Qualitative Research and Online Conferencing}

In considering how girls' online interactions with friends might be documented for research, three critical questions emerged. First, how can girls' friendship interactions in online contexts be generated and measure for research? Second, how can these interactions be ethically and respectfully generated? And third, how can teenage girls be encouraged to participate and share personal experiences with an adult/ researcher they do not know? These questions provide the framework for the following discussion.

A sociological perspective that typically focuses on the ways in which people manage and negotiate social interaction comes from the work of Erving Goffman. Although Goffman $(1959,1967,1986)$ theorised social interaction well before the advent of the internet and social media, his conceptual resources and framework are frequently deployed to investigate social interaction and self-presentation online (see, for example, Richey, Ravishankar and Coupland, 2016). Important to this study are the ways in which he describes how people negotiate encounters and employ strategies to communicate, and provides a systematic approach for coming to understanding how young people (in this case, teenage girls) construct and portray friendships through online interaction. While his theory of social interaction does not answer all the questions I have about teenage girls' online friendships, at the most basic level, his ideas offer a way of mapping the 
interactional order of their friendship, understanding the impact and power of their friendship talk, noticing the practices and strategies used to negotiate challenges, and highlighting social risks taken to maintain or break the social order of friendship.

Understanding how social experience is organised and governed by key interactional principles is critical to understanding girls' friendship interaction. Goffman's (1986) framework helps bring into focus the ways in which individuals play with unstated rules and rituals to negotiate, manage, and/or impress others to maintain the status quo or protect personal dignity. According to him, every social event is framed by key expectations, obligations, rituals and rules of conduct. These rules are reasonably consistent within a frame of activity making particular kinds of social experiences more or less predictable and orderly. However, for any number of reasons, seemingly benign encounters can be pushed into critical moments of challenge and difficulty.

According to Goffman (1986), the predictability of social encounters makes contraventions and rule breaking episodes conspicuous. He referred to these moments as ritual transgressions (1967) and argues that this "spate of activity" (1986, p. 345) provides a great deal of insight into the expectations and framing rules of any social encounter. Moreover, turn-by-turn interactions double as personal strategies to maintain social face. Goffman (1959) referred to this activity as impression management. Attempts to avoid loss of face can push at the boundaries of ritual politeness forcing intentional efforts to protect personal character and maintain social status. Together, both protective and defensive strategies and the order of interactions comprise a modus operandi and social system useful for mapping social interaction across situations regardless of context. Goffman went on to explain that when an individual plays the same part or role with the 
same kind of audience on different occasions, pre-established patterns of interaction unfold. That is, social roles emerge and routines, expectations, obligations, rituals and rule of conduct for the occasion become apparent. He suggested that observing these arrangements offers points of reference for understanding the interactions of other groups of individuals of a similar nature (in this case other girls in friendship groups). Such occasions also offer insight into the discursive resources used by group members to shape interactional performances, guide impression management practices, and constitute social identities within set relationships. With this logic in mind, I understood observing and mapping turn-by-turn encounters of girls' friendship interactions as having potential to provide insight into the social "workings" (Goffman, 1986, p. 28) of their daily practice both individually and in groups. Identification of representative patterns of girls' interaction with friends was expected to lead to better understanding of their friendship practices in and out of school, both on and offline.

Observation seems a fundamental method for mapping representative patterns of girls' interactions with friends. However, early recruitment efforts demonstrated that many Year 8 girls were not keen to share their online friendship experiences with an unknown adult-researcher, especially one that closely resembles a mother. Big Brother strategies and other covert methods were deemed highly unethical. Hence, a different approach for eliciting talk and providing examples of what girls do, how they speak to each other, how they manage impressions, and how they navigate challenging moments was needed. While Goffman (1986) is adamant that natural observation is key to understanding everyday interaction, he also suggests that any type of encounter between key actors is a prime site for mapping the expectations, obligations, routines, rituals, and 
rules of conduct that guide interactional practice. Although segments of interaction are mostly unique in terms of content and outcome, Goffman points out that individuals manage, navigate and control their interactional turn in a more or less orderly progression, that is, a my turn-your turn progression. This progression follows particular rules and routines characterised by roles or positions (e.g. best friend) and group purpose (e.g., friendship). Goffman (1983) describes this progression as the "interaction order" (p. 1). He argues that the interaction order provides a map of sorts into the daily practices and strategies of individuals in everyday settings and, in this way, the order becomes a useful resource for systematically charting and analysing daily encounters within set groups. As previously mentioned, this idea suggests observing an individual in one context has potential to highlight their practices and strategies in comparable situations. Therefore, for this study, it was theorised that tracing teenage girls' interaction with friends in group encounters would offer something in terms of understanding their interactions with friends in other social spaces such as online contexts. To some extent this view was supported by the girls themselves in that they understood "chatting" and "hanging out" with friends to include a collation of practices across various face-to-face spaces and digital contexts. For most, interaction with friends was a free-flowing overlapping practice embedded across multiple communication channels, not consciously online or offline. The opportunity to chat with friends and share ideas for research seemed to fit this criterion (Thompson, 2016a). However, selecting a research context where the girls could freely interact and talk with friends about online experiences needed an element of privacy. A space was needed where they could actively engage with each other to discuss online practices, strategies, and experiences without fear of 
reprisal or social harm from others. Protecting personal privacy as well as minimising researcher presence was also important.

Coincidentally, one school was testing an online conferencing system called Elluminate Live $^{\mathrm{TM}}$ (this system has since been acquired by Blackboard Collaborate $^{\mathrm{TM}}$ ). I observed teachers and students using Elluminate Live ${ }^{\mathrm{TM}}$ for online tutorials. The system offered a simple, convenient, and reliable space for collaborative activities. It housed several synchronised communication devices including an instant-message application, a live-chat feature with personal headset and microphone, participant feedback tools (e.g., a hand-raising option), video capacity, PowerPoint display, and an interactive whiteboard complete with design tools (e.g., paint brush, highlighting pens, text box feature, and so forth) (see Figure 1). Each feature provided online members with multiple ways to communicate and engage in session content. Any combination of these tools had potential to create a lively, interactive, and collaborative space with a moderate level of anonymity (e.g., group members were numbered not named and participation from different computers was possible). Besides these benefits, the platform had in-built recording and archiving facilities appropriate for data aggregation and storage. The capacity to moderate sessions from another space was a significant feature. After a few trial runs with the school technical expert, I decided Elluminate Live $e^{\mathrm{TM}}$ offered the context I was looking for, an interactive and collaborative online space with capacity for discrete observation. However, the context was not without challenge. Conducting research with teenage girls in a virtual space required considerable planning and thoughtful preparation. 
Insert Figure 1. Elluminate Live ${ }^{\mathrm{TM}}$ synchronised communication devices.

\section{Dedicated online activities}

A major challenge cited by youth researchers is finding ways to encourage and maintain active participation and in-depth contributions from young people about private and/or sensitive topics. Part of the problem stems from a general lack of commitment from young people to do research but also, the tricky activity of motivating them to critically and/or affectively engage in research activities. For example, Bassett et al. (2008) found teenage participants often considered research to be "a chore" (p. 124) and noted this "activity-oriented approach" (p. 124) precipitated in poor patterns of contribution such as one-word answers (e.g., yes or no responses without elaboration). For this study, it was crucial that the research context encouraged girls to go beyond one-word answers. Examples of girls actively interacting with other girls were needed.

Processes and strategies for eliciting research contributions from young people have been recommended by a number of youth researchers. A key recommendation is the incorporation of familiar artefacts and visual materials such as photographs, illustrations and video clips into data generation processes (Barter and Renold, 2000; Danby et al., 2011; Hazel, 1995). The scholars cited found familiarity captures interest, encourages reflective thinking, and provides reassurance for ideas and opinions. As Hazel (1995) explains, a visual anchor such as a picture or photograph improves confidence and expands imagination by offering an outline for forming opinions and sharing ideas. Jenkins et al. (2010) suggest using developmental vignettes or open-ended stories about other people's experience with the research phenomena. They recommend developmental 
vignettes not only because they help to contextualise the problem in terms understood by young people, but also because they provide opportunities to apply concepts and solutions to someone other than oneself. Jenkins et al. note that young people are much more likely to elaborate on a vignette character's plight than share their own experiences or views directly. They found vignettes provided an avenue for eliciting ideas or memories about personal experiences that did not compromise participants' confidentiality and need for privacy.

Interactive partnerships have also been promoted as effective mechanisms for encouraging young people to share and elaborate ideas. For example, Mallan et al. (2013) used dedicated interactive websites (i.e., blogs and discussion forums) to encourage participants to respond to and ask questions of their peers. Because individuals could "choose their own particular form of participation and non-participation" (p. 118-119), "dominate-subordinate relationships" (p. 117) between researchers and young people were minimised and ideas flowed more smoothly. Punch (2002) also recommends incorporating interactive activities into research contexts. She explains how sharing activities with other participants creates a relaxed and engaging atmosphere which prods young people to explore issues more broadly and encourages them to formulate and expand on abstract ideas and personal experiences. Punch points out that young people have different interactional styles, levels of confidence, and personal interests so it is important to include a variety of activities to produce data. Of course, digital technologies are generally accepted as critical tools for engaging young people in contemporary research (Flanagan et al., 2015). 
Building on and extending ideas discussed above, I designed four group activities in Elluminate Live ${ }^{\mathrm{TM}}$ using PowerPoint and video clips as presentation tools. The activities were designed to provide the girls with opportunities to interact with each other, to share ideas with confidence, and to elaborate on points of significance. The girls had varying levels of technical skill so the first activity was a training session. The objective was to develop confidence with the equipment and build rapport between participants. The second activity asked the girls to respond to simple questions about a set of emoji illustrations (see Figure 2). The emoji-style illustrations were similar to typical online examples but different enough to stimulate discussion.

Insert Figure 2. Examples of emoji illustrations.

The next activity involved analysis of two publicly available video clips. Video One was 32 seconds long and depicted a kitchen scene where four girls meet to do their homework. The conversation between the actors quickly turns nasty, trouble arises and name-calling eventuates. Video Two was 62 seconds long and illustrated how gossip, rumours, and untruths travel to classmates quickly through mobile devices. After viewing each video, the girls were asked three key questions to encourage group discussion: i) what was happening in the scene, ii) how do you think the character was feeling, and iii) what is the key message in the clip? Girls' answers often channeled discussion in interesting and unexpected directions (see examples in sections to follow).

The final activity involved interpretation of two line-art illustrations. The first illustration showed a teenage girl engaged with several contemporary technologies (see 
Figure 3). In the second illustration, the same girl was shown in a sequence of events involving a mobile phone and a group of friends (see Figure 4). The activity involved working together as a group to create a story about the character's circumstances. All activities were deliberately scaffolded starting with simple questions that gradually led to more complex levels of interpretation and analysis.

Insert Figure 3. Illustration of teenage girl using several technological devices and social media.

Figure 4. Illustration of sequenced events involving a mobile phone and group of teenage friends.

\section{Going live: Spontaneous interaction}

The 16 girls who agreed to participate in the Elluminate Live $e^{\mathrm{TM}}$ sessions were divided into four groups of four. Each group included friends from their homeroom class (i.e., pastoral care or tutorial class). For each session, girls were stationed in the school technology lab with a desktop computer, corresponding mouse and headset with microphone. The computer room was deemed the best option for these sessions because it offered uniformity in hardware and functionality plus technical support. Technical support proved to be crucial for two reasons. First, none of the girls had used online conferencing tools before and, therefore, needed some guidance. Second, at the start of each session some girls were very noisy and a bit unruly. They were talking and calling out to each other and not using their microphones. Some were distracting others ("Hi Tanya, hi Tanya ... TANNYYAAAAA! Put your head phones on") and a few needed extra assistance (“I'm confused. What's going on? Who said hello?”). Technical staff spent several minutes encouraging girls to settle down and participate from their own computer. The close proximity of other girls and low-level supervision in the technology 
lab meant a lot of sharing occurred. Sharing was not considered overly problematic except when turmoil drew attention from teachers in close-by rooms. One neighbouring teacher firmly reprimanded a group of girls. "You are sharing things REALLY REALLY LOUDLY. When you talk, use the microphone!" Reminding girls to use their microphones throughout group activities became standard procedure.

From start to finish of online conferencing activities, the girls enthusiastically engaged with each other. Spontaneous multi-modal communication and overlapping conversations emerged. A screenshot of girls' interactions during a training session is shown in Figure 5. While screen capture does not replicate the lively nature of the girls' interaction, the image shows the multi-modal nature of the context (e.g., talking, texting, writing, drawing, listening). Sessions ran for approximately 40 minutes. Girls remained fully engaged throughout this time constantly interacting with other group members. The interactions presented below provide instances of how the online conferencing context created a space for teenage girls to talk about, share, and articulate examples of their interactional practices with friends.

Insert Figure 5. Girls' interaction in online conference training session.

In the excerpt below, Yasmine has taken up the activity of erasing the online interactive whiteboard. Two girls, Shona and Dana try to take over the activity. A pithy exchange between the girls ensues, moving spontaneously between live chat and text messaging.

Researcher: We can erase the interactive whiteboard now. Yasmine: I will! Shona and Dana: I will!

Dana: I want to! 
Yasmine: I'm doing it!

Shona: I'm doing it!

Dana: It's erasing for me!

Yasmine: I did it! (Shifts to text messaging) I DID IT DANA GRRR

Dana (Shifts to text messaging): WTF

Shona: I yi yi

The shift from live chat to text messaging is a strategy Yasmine uses to briefly contest Dana's challenge. Yasmine ignores Dana's response ("WTF"). Instead, she quickly draws on the next interactive slide before the other two girls can respond. The strategy is simple but effective. The encounter leaves Dana subdued, and it is several minutes before she re-engages in the discussion. In contrast, Shona makes loud irritating noises whenever Yasmine contributes to the discussion. When Dana finally contributes again, Shona shows her support by loudly agreeing with her. "Yah, what Dana said, yah, what Dana said ... I AGREE!" Shona continues to counter Yasmine's contributions for several minutes and progressively increases the intensity of her verbal attack until Yasmine firmly tells her to "BE QUIET" and "STOP GRUMBLING!"

The exchange between the girls demonstrates how efforts to control the social order and maintain the status quo can quickly shift ordinary talk to terse interaction. The girls are fast to employ strategies to undermine the practices of others. They seamlessly and simultaneously shift their interactions across communication modalities to get this self-work done (Goffman, 1986). The encounter highlights how threats to the interaction order and the established rules of conduct quickly disrupt the girls' comradery. The online conferencing context made visible patterns of challenge in girls' interactional practice as well as informal moments of online texting that are often closed off to adult inspection. These are two important aspects of contemporary friendship in online contexts. 


\section{Encouraging discussion with visuals}

The following live chat took place between two girls during a discussion about Figure 4. Other girls in their group were talking about how they would feel if they were not allowed to use their mobile phones until the end of the school day (i.e., at 3:20pm). Below, Jayne and Lisa have a side-line conversation about access to mobile phones.

Researcher: How would you feel about that?

Lisa: That's not good!

Jayne: I wouldn't really care.

Lisa: I would.

Jayne: I'm not like attached to my mobile phone...I...uuummm...don't really worry about that.

Lisa: You don't even have one (loud)

Jayne: Yah I do (defensive)

Lisa: Do you? You never have it at school.

Jayne: Whot?

Lisa: Do you use your mum's?

Jayne: I don't. I don't. When I had it, I wouldn't really use it during the day (voice fades).

Lisa: I use it a lot!

When Jayne says a mobile phone is not really that important to her ("I wouldn't really care”), Lisa questions her indifference by saying "you don’t even have one”. Jayne tries to speak up (“yah, I do") but Lisa continues to question her ("Do you?"). She then goes on to say, "you never have it at school" suggesting that she has been monitoring Jayne's phone use. In the end, Jayne's explanation has not repaired the damage although she makes a brave attempt to reclaim her position with a revised story ('I don't. I don't. When I had it, I wouldn't really use it during the day."). At the end of the exchange, Lisa makes her position clear -“I use it a lot!" She manages to align her phone practice to teenage girls' normative view on mobile phones (i.e., they are very important) and, in this way, shows commitment to the status quo for girls her age (e.g., I have one and I use it a 
lot). The exchange between the two girls highlights how mobile phones have become a necessary teenage girl accessory. Teenage girls who do not possess a mobile phone are not cool, equally bad if they use their mother's phone instead of having their own device.

This is an important exchange. It highlights the complex work of constructing an identity to align to group standards but also shows how this work is co-constructed in and through girls' everyday talk. The features of the online conference platform along with the visual stimulus (Figure 4) provided both the means and the context for this conversation to take place.

\section{Remote presence}

One of the fundamental principles that underpinned the research design involved maintaining the girls' active agency during focus group discussions. Minimising researcher presence was considered important to this aim and, therefore, remote access was deemed a significant feature of the online conference platform. However, the 'feel' of my remoteness and, therefore, the roles I undertook as a researcher seemed to fluctuate between being an asymmetrical, overseeing adult to a participating player to an overhearing non-participating group member (Danby, 1997). There were many occasions when girls moved to side-line conversations with friends. The off-topic nature of these conversations suggested they had forgotten about me. Briefly, I became an overhearing non-participant. The excerpt below highlights one such moment. In this excerpt, two girls (Cynthia and Jennifer) are talking through the live chat feature about a picture posted on

the interactive whiteboard. It is an emoticon representing a make-up or beauty treatment.

Cynthia: That looks like my Mum (laughing)

Jennifer: That looks like my Mum! (louder, laughing)

Cynthia: That looks like my Mum! (very loud)

Jennifer: I know right! 
Cynthia: I gave my Mum an oatmeal facial...

Jennifer: Hee hee!

Cynthia: And she spewed on me. It wasn't nice. I slapped her. Joke! I would neverrrr do that to my Mum.

Emily: Researcher's Name! (very loud)

The girls banter back and forth in good humour until Emily calls out my name. The callout reminds them that I am present even in my remote capacity. It is not certain whether the call-out is a prompt for the girls to be careful about their talk or if Emily is uncomfortable with the girls sharing these ideas while I am listening as an overseeing adult. Other similar examples emerged. In the excerpt below, Jacinta, using live chat, is sharing a story about online problems experienced with school friends.

Jacinta: I have a personal story

Researcher: Oh, okay.

Girls are giggling in the background.

Jacinta: Wellll, uummm

Researcher: Did it turn out okay?

Jacinta: No...errr...yeah...sort of

Researcher: Sort of?

Jacinta: Some people started saying that I'm mean and stuff and then it turned into a bigger lie.

Researcher: So, how did you handle that?

Jacinta: Uuummmm...I don't remember...I think I just told people that it is not true.

Jade: Excuse me? (loud)

Researcher: Yes?

Jade: Is it supposed to have like all the screens going through like that?

Jacinta is interrupted by Jade. Jade's interruption shifts attention away from her. A new topic is raised, and the story is gone. This disruption may have been a strategy used by Jade, so Jacinta doesn't have to answer the question, or the technical problem might have been truly significant to Jade. In either case, Jade's interruption moves me from participating player to overseeing adult once again. 
The ways in which the girls used my remote presence to manage and negotiate the interactions of others significantly shaped the course and direction of focus group discussions. These actions speak to the strategic nature of girls' everyday interactional practice with each other but also show their capacity to circumvent the adult world to manage their social self (Goffman, 1986). While remote presence was a strategy I used to encourage natural discussion amongst the girls, they quickly turned it into a strategic tool to manage and negotiate group interaction.

\section{Conclusions}

Conducting focus group discussions with teenage girls in an online conference platform was not straightforward. Creating and maintaining this research environment was laborintensive and inordinately messy. Visual supports required a great deal of planning and preparation. However, planning time was well spent as girls remained actively engaged throughout the session and most agreed they enjoyed the activity ("it was really cool and fun" - Jayne). Low-level supervision did create some behavioral problems which disrupted nearby lessons, therefore, prompting and reminding participants of behavioural expectations is an essential protocol. Technical support is also crucial. The girls needed more assistance than expected but providing support at the start of each session helped to effectively manage differences in participant skill level.

Despite these challenges, the online conferencing platform created an engaging research environment that successfully accessed a sensitive set of actions, practices and interactions typically difficult to observe for research purposes. The research activities and the context encouraged active and sustained participation from the girls. This commitment alleviated poor patterns of communication and motivated the girls to 
critically and/or emotionally commit to the research (Bassett et al., 2008). Dedicated interactive activities allowed the girls to choose their own style of participation (Mallan et al., 2013) in a relaxed and engaging atmosphere. The online design created a balance between: i) engaging the girls in discussion about their online experiences with friends, ii) providing them with a safe space to share personal experiences about topics that affect their everyday lives ("thank you Roberta for the chance to have my say xx" - Dana), iii) generating good quality interactional data relevant to the research under investigation, and iv) mapping the interaction order (i.e., the 'my turn, your turn' progression) of teenage girls' communication with friends. overall, the research context was challenging. However, the platform and group activities provided many opportunities for the girls to demonstrate how they speak to each other, manage their online presence, and circumvent online troubles with friends - a key focus of the doctoral research.

\section{References}

Australian Communications and Media Authority [ACMA]. (2008). "Media use by girls and boys, Report No. 2". Media and Communication in Australian Families Series. Available at: www.acma.gov.au/webwr/_assets/main/lib310665/no2_media_use_by_girls_and_bo ys.pdf

Author (2016a).

Author (2016b)

Barter, C., \& Renold, E. (2000). "I wanna tell you a story: Exploring the application of vignettes in qualitative research with children and young people". International Journal of Social Research Methodology 3(4), 307-323. Avaiable at: doi:10.1080/13645570050178594

Bassett, R., Beagan, B.L., Ristovski-Slijepcevic, S., \& Chapman, G.E. (2008). “Tough teens: The methodological challenges of interviewing teenagers as research participants." Journal of Adolescent Research 23(2): 119-131. Available at: doi: 10.1177/0743558407310733

Cross, D., Li, Q., Smith, P.K., \& Monks, H. (2012). "Understanding and preventing cyberbullying.” In Q. Li, D. Cross, \& P.K. Smith (Eds.), Cyberbullying in the global 
playground: research from international perspectives. West Sussex, UK: WileyBlackwell, pp. 287-305.

Cross, D., Shaw, T., Hearn, L., Epstein, M., Monks, H., Lester, L., \& Thomas, L. (2009). Australian Covert Bullying Prevalence Study [ACBPS]. Perth, WA, Australia: Child Health Promotion Research Centre, Edith Cowan University.

Danby, S. (1997). "The observer observed, the researcher researched: The reflexive nature of phenomena." Paper presented at the Australian Association for Research in Education Annual Conference, Researching Education in New Times, Brisbane, Australia.

Danby, S., Ewing, L., \& Thorpe, K. (2011). "The novice researcher: Interviewing young children." Qualitative Inquiry, 17(1), 74-84. Available at:

doi: $10.1177 / 1077800410389754$

Flanagan, S.M., Greenfield, S., Coad, J., \& Neilson, S. (2015). "An exploration of the data collection methods utilised with children, teenagers and young people (CTYPs)". BioMed Central Research Notes 8(61), 1-14. Available at: doi: 10.1186/s13104-015-1018-y

Goffman, E. (1959). The presentation of self in everyday life. St Ives, UK: Penguin Books.

Goffman, E. (1967). Interaction ritual: Essays on face-to-face behaviour. Ringwood, Victoria, Australia: Penguin Books.

Goffman, E. (1983). "The interaction order: American Sociological Association, 1982 Presidential Speech.” American Sociological Review 48(1), 1-17. Available at: http://www.jstor.org/stable/2095141

Goffman, E. (1986). Frame analysis: An essay on the organization of experience. Lebanon, NH: University Press of New England.

Hazel, N. (1995). "Elicitation techniques with young people." Social Research Update, Winter (12), 1-7. Available at: http://sru.soc.surrey.ac.uk/SRU12.html

Jenkins, N., Bloor, M., Fischer, J., Berney, L., \& Neale, J. (2010). "Putting it in context: the use of vignettes in qualitative interviewing." Qualitative Research 10(2), 175198. Available at : doi: $10.1177 / 1468794109356737$

Koocher, G. P. (2002). "Using the CABLES model to assess and minimize risk in research: Control group hazards.” Ethics \& Behavior, 12(1), 75-86.

Available at: doi: 10.1207/S15327019EB1201_5

Livingstone, S., \& Haddon, L. (2009). EU Kids Online: Final report. Available at: http://www.lse.ac.uk/media@1se/research/eukidsonline/eu\%20kids\%20i\%20\%28200 6-9\%29/eu\%20kids\%20online\%20i\%20reports/eukidsonlinefinalreport.pdf

Mallan, K., Singh, P., \& Giardina, N. (2013). "Tech-savvy youth and participatory research in 'iScapes'”, in Deliyanni, K. \& Chisholm, L. (Eds.), Changing landscapes of childhood and youth in Europe. Cambridge Scholars Press, Cambridge, UK, pp.111-128. 
Nguyen, B., McGregor, K., O'Connor, J., Shrewsbury, V., Lee, A., Steinbuck, K., . . . Baur, L. (2012). "Recruitment challenges and recommendations for adolescent obesity trials." Journal of Paediatrics and Child Health, 48, 38-43. Available from: doi: 10.1111/j.1440-1754.2011.02183.x

Patchin, J., \& Hinduja, S. (2012). "Cyberbullying: An update and synthesis of the research", in Patchin, J. and Hinduja, S. (Eds.), Cyberbullying prevention and response: Expert perspectives), Routledge, New York, NY, pp. 13-35.

Punch, S. (2002). "Interviewing strategies with young people: The 'secret box', stimulus material and activity-based activities." Children \& Society 16, 45-56. Available at: doi: 10.1002/chi.685

Richey, M., Ravishankar, M.N.,\& Coupland, C. (2016). Exploring situationally inappropriate social media posts: An impression management perspective. Information Technology and People,29(3), pp.597-617.

Ringrose, J., Harvey, L., Gill, R., \& Livingstone, S. (2013). Teen girls, sexual double standards and sexting: Gendered value in digital image exchange. Feminist Theory 14(3), 305-323. Available at: doi: 10.1177/1464700113499853 